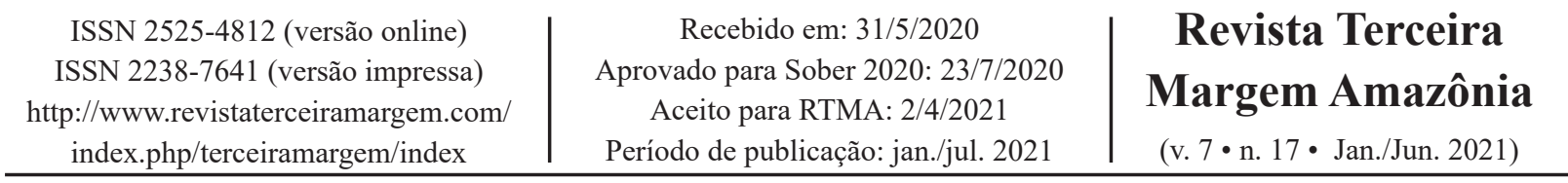

Como citar o artigo:

COSTA, G. B; SANTOS, A. C.; SILVA, L. de J. de S; MENEGHETTI, G. A. Reflexões sobre a permacultura no Amazonas: uma abordagem a partir da experiência do Instituto de Permacultura da Amazônia (IPA). Revista Terceira Margem Amazônia. v. 7 , n. 17, p. 207-223, 2021. DOI: http://dx.doi.org/10.36882/2525-4812.2021v7i17.p207-223

\title{
REFLEXÕES SOBRE A PERMACULTURA NO AMAZONAS: UMA ABORDAGEM A PARTIR DA EXPERIÊNCIA DO INSTITUTO DE PERMACULTURA DA AMAZÔNIA (IPA)
}

\author{
Glenda Barbosa da Costal \\ Alessandro Carvalho dos Santos ${ }^{2}$ \\ Lindomar de Jesus de Sousa Silva ${ }^{3}$ \\ Gilmar Antônio Meneghetti ${ }^{4}$
}

\begin{abstract}
Resumo: O texto analisa de forma breve a história da permacultura no Brasil e no Amazonas, identificando projetos e experiências existentes no País. Faz uma abordagem dos conceitos a partir da visão de diversos autores e analisa as suas contribuições a partir da experiência do Instituto de Permacultura da Amazônia (IPA). A permacultura surgiu na década de 1970, criada pelos cientistas australianos Bill Mollison e David Holmgren, que sistematizaram tecnologias ancestrais e atuais de diversas áreas do conhecimento para que pudessem ser usadas na criação e estruturação de assentamentos humanos sustentáveis. O conceito chegou definitivamente no Brasil em 1990 e, com o intuito de consolidar essa ideia no Amazonas, em 1997, foi criado o IPA, com a missão de difundir os princípios, as técnicas e a metodologia no estado do Amazonas, principalmente nas comunidades rurais. Para a elaboração deste artigo realizou-se uma pesquisa bibliográfica, exploratória e investigativa, com entrevistas semiestruturadas e buscas nas redes sociais e na rede mundial de computadores por iniciativas nessa área, a partir das quais se analisou o atual estágio da experiência do IPA. A experiência desse instituto demonstrou que a permacultura é uma forma de desenvolvimento da agricultura que integra um conjunto de ações e estruturas de forma coordenada e complementar, harmônica e integrada à vida das pessoas, visando à sustentabilidade do sistema, das
\end{abstract}

\footnotetext{
Bolsista de Iniciação Científica, Paic/Fapeam/Embrapa Amazônia Ocidental, Manaus, AM.

E-mail: costaglenda900@gmail.com

(D) https://orcid.org/0000-0002-0821-7744

2 Graduando em Economia na Universidade Federal do Amazonas, Manaus, AM.

E-mail: alessandrocarvalho1999@gmail.com

(D) https://orcid.org/0000-0003-0116-7155

3 Sociólogo, doutor em Desenvolvimento Sustentável do Trópico Úmido, pesquisador da Embrapa Amazônia Ocidental, Manaus, AM.

E-mail: lindomar.j.silva@embrapa.br

(D) https://orcid.org/0000-0002-4816-486X

4 Engenheiro-agrônomo, mestre em Desenvolvimento Agricultura e Sociedade, pesquisador da Embrapa Amazônia Ocidental, Manaus, AM.

E-mail: gilmar.meneghetti@embrapa.br

(iD) https://orcid.org/0000-0001-5645-8916
} 
atividades com a preservação do ambiente. Para consolidar essa ideia, o IPA desenvolveu a Unidade Demonstrativa de Permacultura (UDP), que propiciava o conhecimento sobre o tema, realizava cursos sobre permacultura e temas correlatos, e foram estruturados modelos de construções que podem ser replicados em comunidades rurais.

Palavras-chave: permacultura, Instituto de Permacultura da Amazônia, sustentabilidade.

\title{
REFLECTIONS ON PERMACULTURE IN AMAZONAS: AN APPROACH FROM THE EXPERIENCE OF THE INSTITUTE OF PERMACULTURE IN THE AMAZON
}

\section{(IPA)}

\begin{abstract}
The text briefly analyzes the history of permaculture in Brazil and Amazonas, identifying projects and experiences existing in the country. It approaches concepts from the perspective of several authors and analyzes their contributions, based on the experience of the Instituto de Permacultura da Amazônia (IPA). Permaculture emerged in the 70s and was created by Australian scientists Bill Mollison and David Holmgren, who systematized ancestral and current technologies, from different areas of knowledge, so that they could be used in the creation and structuring of sustainable human settlements. The concept finally arrived in Brazil in 1990 and, in order to consolidate this idea in Amazonas, in 1997 the Amazon Permaculture Institute (IPA) was created, with the mission of spreading the principles, techniques and methodology in the state of Amazonas, mainly in rural communities. To meet the objective, IPA created the UDP (Permaculture Demonstration Unit). For the preparation of this article, a bibliographical, exploratory and investigative research was carried out, with semistructured interviews and searches on social networks and the worldwide computer network of initiatives in this area, from which the current stage of the experience of the Instituto de Permaculture in the Amazon. The IPA experience has shown that permaculture is a form of agricultural development, which integrates a set of actions and structures, in a coordinated and complementary way, harmonious and integrated into people's lives, aiming at the sustainability of the system, of activities with preservation of the environment. In order to consolidate this idea, IPA developed the UDP, which provided knowledge on the subject, carried out courses on permaculture and related topics, and building models were structured that can be replicated in rural communities.
\end{abstract}

Keywords: permaculture, Amazon Permaculture Institute, sustainability.

\section{Introdução}

A permacultura ${ }^{5}$ articula um conjunto de conhecimentos das mais diversas áreas, como meio de reconhecer padrões naturais, desenvolver técnicas de manejo, aproveitar os recursos naturais e desenvolver ambientes humanos de forma produtiva e sustentável, em equilíbrio com o ecossistema. A permacultura foi concebida como um método de agricultura permanente no fim dos anos 1970, o conceito chegou efetivamente no Brasil no início dos anos 1990, com a visita de Mollison, que realizou cursos no Amazonas e no Rio Grande do Sul.

No Amazonas, em 1997, foi criado o IPA, com a missão de disseminar a metodologia no estado, principalmente nas comunidades rurais. Esse instituto criou a UDP, localizada na zona leste de Manaus, na Escola Agrotécnica de Manaus, atual Instituto Federal do Amazonas (Ifam). Essa unidade serviu de referência de permacultura na região, além de promover um conjunto de ações

\footnotetext{
O termo permacultura tem origem na expressão inglesa "Permanent Agriculture" e tem como criadores Bill Mollison e David Holmgren, na década de 1970 do século passado.
} 
voltadas a capacitar agricultores, professores e agentes sociais em sistemas produtivos integrados e contínuos que possibilitem suprir as demandas e as necessidades das comunidades locais.

A unidade de Manaus tem uma área de 8,6 ha, distribuídos dentro da unidade, com o ambiente de produção animal e vegetal, servindo de laboratório para diversas pesquisas e desenvolvimento de um modelo sustentável para a região amazônica com apoio de mão de obra de estudantes, técnicos, estagiários e funcionários de outras instituições (CARVALHO et al., 2019). O IPA encerrou suas atividades em 2012, passando todos os seus equipamentos e estruturas para o Centro de Referência em Agroecologia (CRA), que é administrado pelo Instituto Federal do Amazonas (Ifam) da zona leste de Manaus.

O presente trabalho faz uma reflexão sobre a permacultura no Amazonas, tendo como fio condutor a experiência do IPA. Sendo assim, o objetivo principal deste trabalho é descrever sobre a permacultura no Brasil e no Amazonas, identificar projetos de permacultura existentes no País, por meio de um levantamento nas redes sociais e na rede mundial de computadores, e analisar o estágio atual da experiência do IPA no Amazonas.

Atualmente a estrutura do IPA é administrada pelo Ifam e passou a denominar-se Centro de Referência em Agroecologia. O IPA foi uma tentativa de a sociedade civil, com apoio de fundações privadas, disseminar a permacultura aos agricultores do Amazonas.

Portanto, o presente texto apresenta os fatores que levaram à desarticulação do IPA, na perspectiva de mostrar aqueles que podem inviabilizar projetos voltados a dinamizar perspectivas sustentáveis nas comunidades rurais, e aponta a questão da sustentabilidade financeira, organizativa e social como principais medidas para os projetos alcançarem êxito em sua missão.

\section{Metodologia}

A presente pesquisa surgiu da necessidade de respondermos às perguntas: o que é permacultura? Que projetos de permacultura estão sendo desenvolvidos no Amazonas? Diante dessas perguntas adotamos a pesquisa bibliográfica, que é definida por Gil (2002, p. 44) como aquela que tem "material já elaborado, constituído principalmente de livros e artigos científicos". Nesse sentido, buscou-se utilizar artigos, livros e periódicos, como também materiais didáticos e informações divulgadas em páginas eletrônicas e redes sociais, que continham a temática da permacultura, tecnologia e inovações voltadas para a sustentabilidade, presentes em serviços eletrônicos de instituições públicas, privadas e movimentos sociais. Essa fase da pesquisa possibilitou o desenvolvimento das práticas de leitura, seleção, fichamento e organização das informações (FACHIN, 2010).

Com base nas informações conseguidas realizamos pesquisa exploratória e investigativa com o intuito de adquirir "maior familiaridade com o problema" (GIL, 2002, p. 41). Nessa fase visitamos o Ifam, localizado na zona leste de Manaus, onde funcionou o IPA até 2012. Durante as visitas foram realizadas entrevistas, que é o "encontro entre duas pessoas, a fim de que uma delas obtenha informações a respeito de um determinado assunto" (MARCONI; LAKATOS, 1999, p. 94). Nessa técnica adotamos a entrevista não estruturada, que permite maior liberdade entre o entrevistado em explorar de forma mais ampla a questão. 
Por fim, quanto à abordagem, classificamos a presente pesquisa como qualitativa, já que não possui uma preocupação com a "representatividade numérica" (GERHARDT; SILVEIRA, 2009, p. 32), e sim que ela seja “capaz de produzir novas informações” (DESLAURIERS, 1991, p. 58).

\section{Revisão da literatura}

O conceito de permacultura foi desenvolvido em 1974 por David Holmgren, ecologista, e Bill Mollison, naturalista, ambos australianos, como pensamento crítico ao modelo industrial, que permitisse aos seres humanos uma alternativa à sociedade industrial e sua permanência no planeta Terra (KRYZANOWSKI, 2005). Permacultura é a junção das palavras permanência e cultura, ou seja, busca a harmonia entre ser humano e a natureza como pressuposto para o cuidado com a terra (HENDERSON, 2012). A permacultura desenvolveu um método holístico para planejar, atualizar e manter sistemas de escala humana ambientalmente sustentáveis, socialmente justos e financeiramente viáveis.

A Confederação das Cooperativas de Reforma Agrária do Brasil - Concrab (1997, p. 22) entende que a "permacultura pode ser definida como um conhecimento que propõe princípios e técnicas para planejar a relação sustentável entre os seres humanos e os recursos naturais, com o intuito de, basicamente, viabilizar a moradia, produzir alimentos saudáveis, conviver harmoniosamente e conservar o meio ambiente".

Para Soares (1998), permacultor e fundador do Ecocentro - Instituto de Permacultura e Ecovilas do Cerrado (Ipec), a permacultura busca possibilitar a integração do homem com o ambiente por meio da análise do ciclo de vida de cada material utilizado; por meio da análise de origem e destino do material, da não utilização de materiais tóxicos (coadjuvantes) e descartáveis; da valorização dos materiais locais; da utilização de técnicas inteligentes de materiais de mercados industriais; da racionalização do uso da água e da promoção de tratamentos naturais dos efluentes (esgoto), reciclagem e reúso; da busca da utilização de fontes de energia renováveis e do trabalho com eficiência energética por intermédio de desenhos arquitetônicos bioclimáticos.

\section{Permacultura com alternativa à produção convencional}

A invenção da palavra permacultura foi motivada pela necessidade de contrapor-se à agricultura convencional, definida por Archer (2015, p. 18) como "um sistema agrícola industrializado, caracterizado pela mecanização, monocultura e uso de insumos químicos como fertilizantes e pesticidas, com ênfase na máxima produtividade e lucratividade. Este sistema tornou-se 'convencional' somente nos últimos 60 anos, desde a II Guerra mundial".

Segundo os inventores da permacultura, a Austrália, na década de 1970, encontrava-se "em estado avançado de degradação ambiental". Essa degradação, para os permacultores, estava diretamente associada à agricultura convencional, por ser uma agricultura de monocultivos em larga escala, que utilizava agrotóxicos, adubos químicos, intensa mecanização e concentração fundiária (CONCRAB, 1997). 
Contrapondo-se ao modelo convencional, a permacultura busca conservar e ampliar a biodiversidade, minimizar o ambiente artificial de desenvolvimento das atividades agrícolas. Com isso se pretende evitar danos irreparáveis decorrentes da grande utilização de insumos químicos e de técnicas padronizadoras de produção. Nodari e Guerra (2015) compreendem a permacultura como um sistema de "visão holística da agricultura, buscando a integração entre a propriedade agrícola e o agroecossistema, com um modelo de sucessão de cultivos visando otimizar a produção e conservando os recursos naturais".

\section{Algumas das principais técnicas da permacultura}

No texto são construídas pela Concrab (1997) sete técnicas da permacultura que podem contribuir para a consolidação de uma agricultura familiar, com efetiva prática sustentável no Amazonas. A primeira técnica é o planejamento por zonas. Na permacultura, o conceito de zona, zoneamento ou setores é a forma como o espaço na propriedade é organizado. Segundo Assis e Romeiro (2002), as zonas são "formas mais simples [...] são círculos concêntricos, mas podem assumir mais formas. As zonas são desenhadas com base no espaço de que dispõem e das funções que estão tentando criar". A Concrab (1997, p. 23) apresenta um desenho mostrando como planejar em zona a propriedade.

No modelo apresentado pela Concrab (1997, p. 23), há seis diferentes zonas no sistema de permacultura:

Zona 0: a zona 0 representa a(s) casa(s) da propriedade. Ela deve ser vista como o centro do sistema; Zona 1: é a área ao redor da(s) casa(s), onde se pode ir várias vezes ao dia sem perder muito tempo. Neste espaço pode ser feito uma horta, por exemplo; Zona 2: esta área é um pouco mais afastada da(s) casa(s), uma área que não demanda um trabalho intenso. Por isso, pode ser um espaço para plantar árvores frutíferas de médio porte ou construir um galinheiro, por exemplo; Zona 3: a zona 3 é ainda mais distante do centro do sistema. Nela pode ser feita uma floresta de alimentos ou um pasto rotativo para bovinos ou caprinos; Zona 4: esta área é pouco visitada. Nela podem ser plantadas árvores madeireiras, pode ser feito um açude, podem ser cultivadas árvores nativas e/ou esta área pode ser aproveitadas para desenvolver um trabalho de extrativismo sustentável; Zona 5: Esta área deve permanecer intacta, sem interferência humana. Nela a vegetação nativa deverá ser preservada para os processos ecológicos naturais servirem de aprendizagem. Este espaço será visitado somente para observação e coleta de sementes.

As zonas possibilitam projetar a área da propriedade de forma a aproveitar melhor cada espaço disponível, reduzir a dependência de insumos externos, valorizar o aspecto climático, como também reduzir tempo e trabalho nas atividades diárias desenvolvidas na propriedade.

A segunda técnica apresentada pela Concrab (1997, p. 24) adotada pela permacultura é a captação e reutilização de água da chuva. As práticas de captação e armazenamento envolvem a "criação de canais de infiltração, que são escavações em curvas de nível que direcionam a água, fazendo com que ela penetre no solo", assim como "construir valas nas estradas próximas ou no próprio local, para também direcionar a água" e a criação de "um sistema de calhas para captar a água que cai do telhado das casas". 
O armazenamento pode ser feito em reservatórios no solo ou suspensos, fechados ou não. Para isso é necessária a construção de tanques, adaptação de caixas d'água ou açudes. A água pode ser utilizada para fins domésticos (tomar banho, cozinhar, lavar e, quando tratada, para beber) e para aguar os plantios e hidratar os animais.

Segundo Ana (2015, p. 1), com o resgate da prática do reúso de água, a permacultura retoma uma atividade "praticada há milhares de anos pela humanidade, mas tem deixado de lado pela falta de parcimônia do ser humano" e que deve fazer parte de "um panorama maior, que deve ser iniciado com o uso racional ou eficiente da água, levando em conta perdas e desperdícios, e a minimização da produção de efluentes e do consumo de água".

As bioconstruções são a terceira prática dos permacultores. Elas consistem em articular conhecimentos de áreas como arquitetura, engenharia e outras. Esse tempo de construção "propõe construções ecológicas adaptadas à região, isto é, que sejam sustentáveis, utilizando matérias-primas locais e/ou plantadas, reaproveitando e reciclando materiais (CONCRAB, 1997, p. 24)". Brasil (2008) afirma que a bioconstrução é a construção de "ambientes sustentáveis por meio do uso de materiais de baixo impacto ambiental, adequação da arquitetura ao clima local e tratamento de resíduos".

Santoro e Penteado (2009, p. 61) entendem que as construções com "um planejamento consciente", que valorizem "as influências e inter-relacionamentos que ocorrem entre os elementos de um sistema vivo", podem contribuir para além de habitações saudáveis, são elementos de sustentação para um futuro seguro em relação aos recursos naturais.

A quarta prática é o mulch, apresentado pela Concrab (1997, p. 25) como "a cobertura do solo, seja ela viva ou morta. A cobertura 'morta', neste caso, pode ser feita até com jornal, e a cobertura 'viva' pode ser feita com, por exemplo, batata-doce ou lab-lab". De acordo com Moura Neto e Nogueira (1994), o uso do mulch de cobertura do solo faz criar uma barreira física à "transferência de energia e vapor d'água entre o solo e a atmosfera" e com isso vai controlar as "plantas daninhas, isolamento do solo no verão, reduzindo a variação da temperatura, o aumento da disponibilidade de nitrogênio e micronutrientes e melhoria da estrutura do solo".

A quinta prática é a floresta de alimentos. Essa prática também é conhecida como agroflorestal e pode ser definida como "policultivo sustentável de alimentos, sendo a maior parte desses alimentos provenientes de árvores de médio e grande portes (CONCRAB, 1997, p. 25). Uma prática que necessita de uma grande diversidade de árvores, principalmente frutíferas.

Arkoll (1982, p. 247) afirma que a "floresta tropical oculta uma vasta quantidade de frutas, castanhas, raízes, caules, seivas, folhas, animais, abelhas fungos e caracóis (lesmas), que podem ter potencial como alimentos domésticos". Segundo o autor, as "florestas de árvores frutíferas ofereceriam também todas as outras vantagens ecológicas de qualquer floresta, tais como controle de erosão e inundações, manutenção do clima".

O sanitário compostável é a sexta prática relacionada pela Concrab (1997) como uma inovação disseminada pela permacultura. Essa inovação consiste em produzir composto com as fezes humanas, como alternativa ao não desperdício e à poluição (COSTA et al., 2019). De acordo com Concrab (1997, p. 25), a ideia básica é "retirar o composto do reservatório de 6 em 6 meses. 
Esse composto pode ser, por exemplo, utilizado no plantio de árvores ornamentais". Como forma de evitar o "mau cheiro, constrói-se uma espécie de chaminé saindo do reservatório. Além disso, utiliza-se matéria orgânica seca, de preferência serragem, para cobrir os dejetos no momento em que o banheiro for utilizado".

Legan (2016) apresenta como vantagens do sanitário compostável: ele não utiliza água para descarga, não produz efluente, não despeja em solos e rios a poluição associada às fezes e não exala mau cheiro.

A sétima prática é o círculo de bananeiras, uma inovação que visa aproveitar melhor os espaços para a produção de mudas de banana. Nessa concepção aproveitam-se os restos vegetais do local sem precisar colocar adubo orgânico. Segundo Concrab (1997, p. 26):

Cava-se um buraco de mais ou menos 1 metro de diâmetro por 1 metro de profundidade; - Com a terra retirada faz-se uma borda em volta do buraco, onde serão plantadas 4 mudas (planta-se nas extremidades da borda - norte, sul, leste, oeste); - Dentro do buraco, pode ser colocado tudo aquilo que for orgânico: pedaços de madeira, galhos caídos, restos de podas, restos de uma "limpeza" em volta da casa, folhas, palha, mato etc.; - Pode-se encher o buraco e ultrapassar a superfície em até 1 metro de altura; - Estes restos vegetais irão se decompondo e alimentando os 4 pés de banana, que deverão ser regados regularmente; - À medida que os cachos de banana vão sendo colhidos, corta-se os troncos, colocando-os dentro do buraco, que ao decorrer do tempo vai "esvaziando" pela decomposição.

Vieira (2006) expõe que o círculo de bananeiras é uma tecnologia pensada para tratar as águas usadas da casa (pias, tanques e chuveiros), as chamadas águas cinzas, e dessa forma beneficiar a produção de bananas em escala humana.

Os levantamentos das informações revelam que a permacultura mostra um grande respeito por todas as formas de vida, o processo natural e o conhecimento tradicional. A permacultura constitui uma alternativa que permite o uso da terra em pequena escala, de modo intensivo, a valorização da diversidade de plantas, a integração com o sistema silvestre (animais e vegetais), a integração da agricultura com pastoreio, reflorestamento, como também a adaptação às chamadas terras marginais, pantanosas, rochosas, inclinadas ou inadequadas a outros sistemas (AMBIENTE BRASIL, 2020). Essas informações serviram de base para o levantamento de informações de práticas e projetos que possuem como orientação a permacultura no estado do Amazonas.

Gostaríamos de salientar que a permacultura é um conjunto de conhecimentos, princípios e técnicas que orientam e integram elementos de forma sustentável, numa visão de complementaridade e preservação de toda forma de vida. Isso significa dizer que o arranjo a ser feito está ligado aos recursos naturais existentes, às características do ambiente, à cultura local. Há princípios e técnicas que orientam, mas o arranjo se dá com base em cada ambiente e região. 
Figura 1. Círculo de bananeiras.

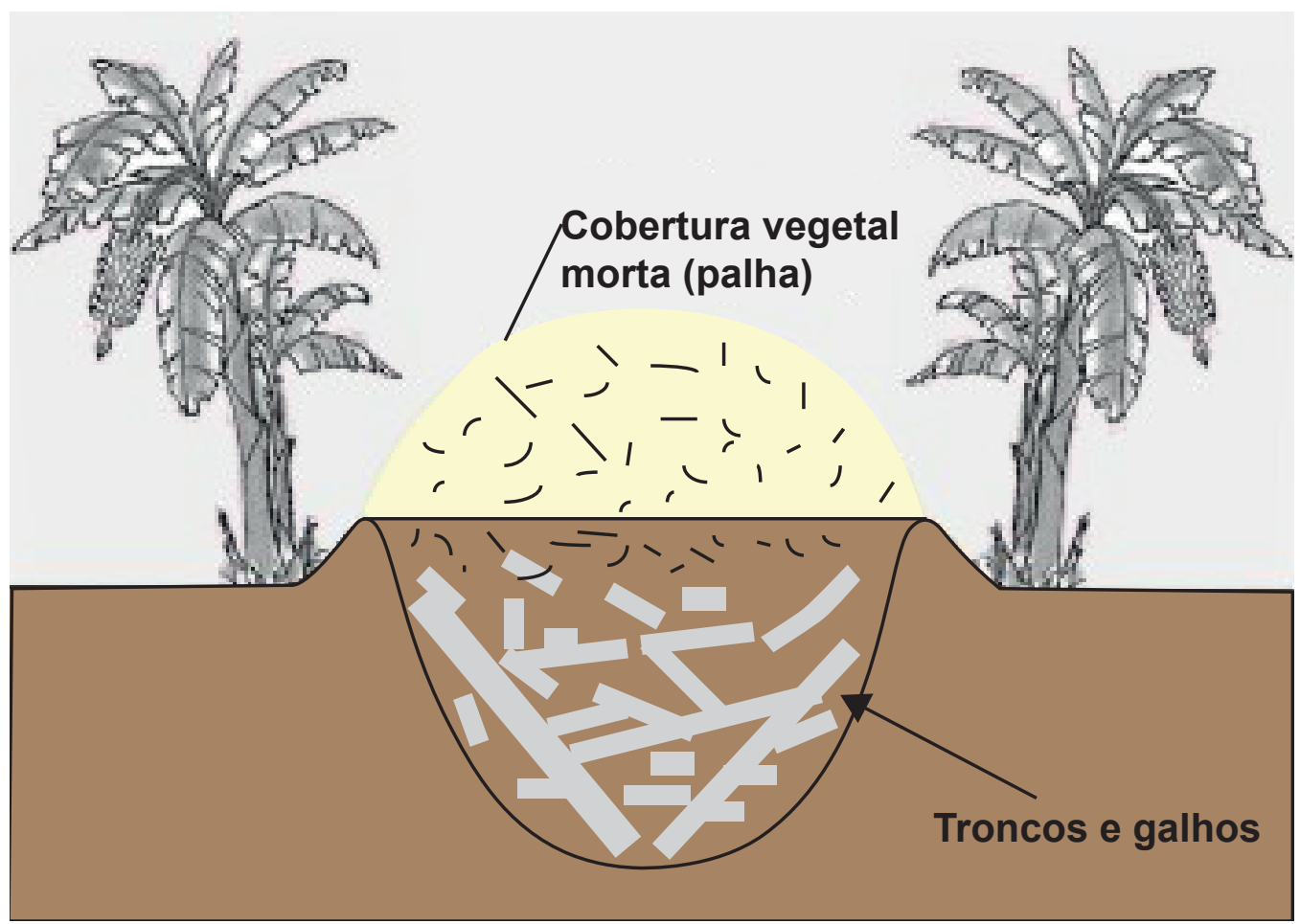

Fonte: Vieira (2006).

\section{Projeto de permacultura no Brasil e seus reflexos no Amazonas}

A palavra permacultura tem origem inglesa, "permanent agriculture”, que traduzida significa agricultura permanente, o que torna sua definição um grande exercício mental, já que não é simples definir permacultura em poucas palavras. No seu desenvolvimento, Bill Mollison e David Holmgren, na Austrália da década de 1970, formularam modelos de interação de culturas ancestrais e a ciência moderna.

Em 1992, o Rio Grande do Sul sediou o primeiro curso de permacultura no Brasil, ministrado por Bill Mollison. Nele se formaram vários permacultores, e todos foram estimulados a multiplicar a permacultura no Brasil e no mundo. Destes, os que hoje conhecemos e lembramos por suas atuações públicas, por assim dizer, são: Cláudio Sanchotene (fundador do IPERS, primeiro instituto do Brasil), Masha Hansi (IPB e depois Epicentro Marizá), Marcos Abrão Cardoso (livraria e editora Via Sapiens) e Alano (Sítio Pé na Terra, RS) (PORÃ, 2017).

Ademais, nesse momento, a permacultura era uma coisa nova, e formar institutos era uma estratégia importante, dando respaldo à fala dos permacultores. Assim, aparecem os novos institutos, visto que o Instituto de Previdência do Estado do Rio Grande do Sul (IPERGS) já existia desde 1992. As novas instituições têm vínculo com Ali Sharif da Permacultura da América Latina (Apal), e vão sendo fundadas em sequência: Instituto de Permacultura da Amazônia (IPA), Instituto de Permacultura e Ecovilas do Cerrado (Ipec), Rede Brasileira de Permacultura (Ipab), Instituto de Permacultura da Pampa (Ipep) e Organização de Permacultura e Arte (OPA). 
No Brasil, atualmente, há um conjunto de projetos voltados a disseminar e fortalecer a prática da permacultura no País. O Instituto de Permacultura (Ipoema), sediado em Brasília, apoia ações em todo o território nacional. A Universidade de Brasília tinha uma disciplina denominada "Introdução à Permacultura", oferecida pelo Departamento de Engenharia Florestal da UnB, do primeiro semestre de 2008 ao segundo de 2011, tendo assim ensinado permacultura para oito turmas, num total aproximado de 240 estudantes de diversos cursos da universidade. As experiências são muitas. Na Tabela 1, listamos algumas experiências e instituições responsáveis pelo desenvolvimento da permacultura no Brasil.

Tabela 1.Projetos com princípios da permacultura no Brasil.

\begin{tabular}{|ccc|}
\hline Projeto & Instituição responsável & Local \\
\hline Programa Juçara & Ipema & Ubatuba-SP \\
Águas do Cerrado & Ipoema & Brasília-DF \\
Permacultura e Agroecologia & Ecovida & Moeda-MG \\
Permacultura Urbana & OPA & Salvador-BA \\
Instituto Pindorama & Pindorama & Rio de Janeiro- RJ \\
Ecocentro & Ipec & Pirenópolis-GO \\
Estação de Permacultura & Setelombas & Siderópolis-SC \\
Rede NEPerma Brasil & Ifes & Florianópolis-SC \\
Escola Rama & Ipep & Bagé-RS \\
Ecoparque & IPB & Salvador-BA \\
EcoOca & ICPTI & Alfredo Chaves-ES \\
Ecovila Dom José & Unipermacultura & Alpestre-RS
\end{tabular}

Fonte: Elaborado pelos autores (2020).

\section{Experiência do Instituto de Permacultura da Amazônia (IPA)}

O IPA surgiu com a ideia dos professores Hamad Ali, Carlos Miller e Moacir Biondo, em 1997, de criar uma organização que pudesse trabalhar permacultura na Amazônia. Diante disso, no Amazonas, criou-se uma Unidade Demonstrativa de Permacultura (UDP), localizada na Escola Agrotécnica de Manaus, atual Ifam. A UDP foi a primeira unidade que serviu de referência para o Brasil em relação a permacultura. Ela foi criada em 1998 com o objetivo de primeiramente recuperar a área degradada do local, depois oportunizar na prática a criação de sistemas produtivos integrados e contínuos que possibilitassem suprir as demandas e necessidades das comunidades locais de forma sustentável (SECA et al., 2019).

A UDP de Manaus tem uma área de 8,6 ha, distribuídos dentro da unidade com o ambiente de produção animal e vegetal, servindo de laboratório para diversas pesquisas e desenvolvimento de um modelo sustentável para a região amazônica, com apoio de estudantes, técnicos e voluntários de outras instituições.

De acordo com o relatório da Fundação Daniel Dazcal (2008), principal mantenedora do projeto de permacultura do Amazonas, a UDP recebeu 1.023 pessoas, entre elas visitantes, estudantes, pesquisadores e comunidades interessadas na cultura. 
Figura 2. Unidade Demonstrativa de Permacultura (UDP) e suas respectivas instalações.

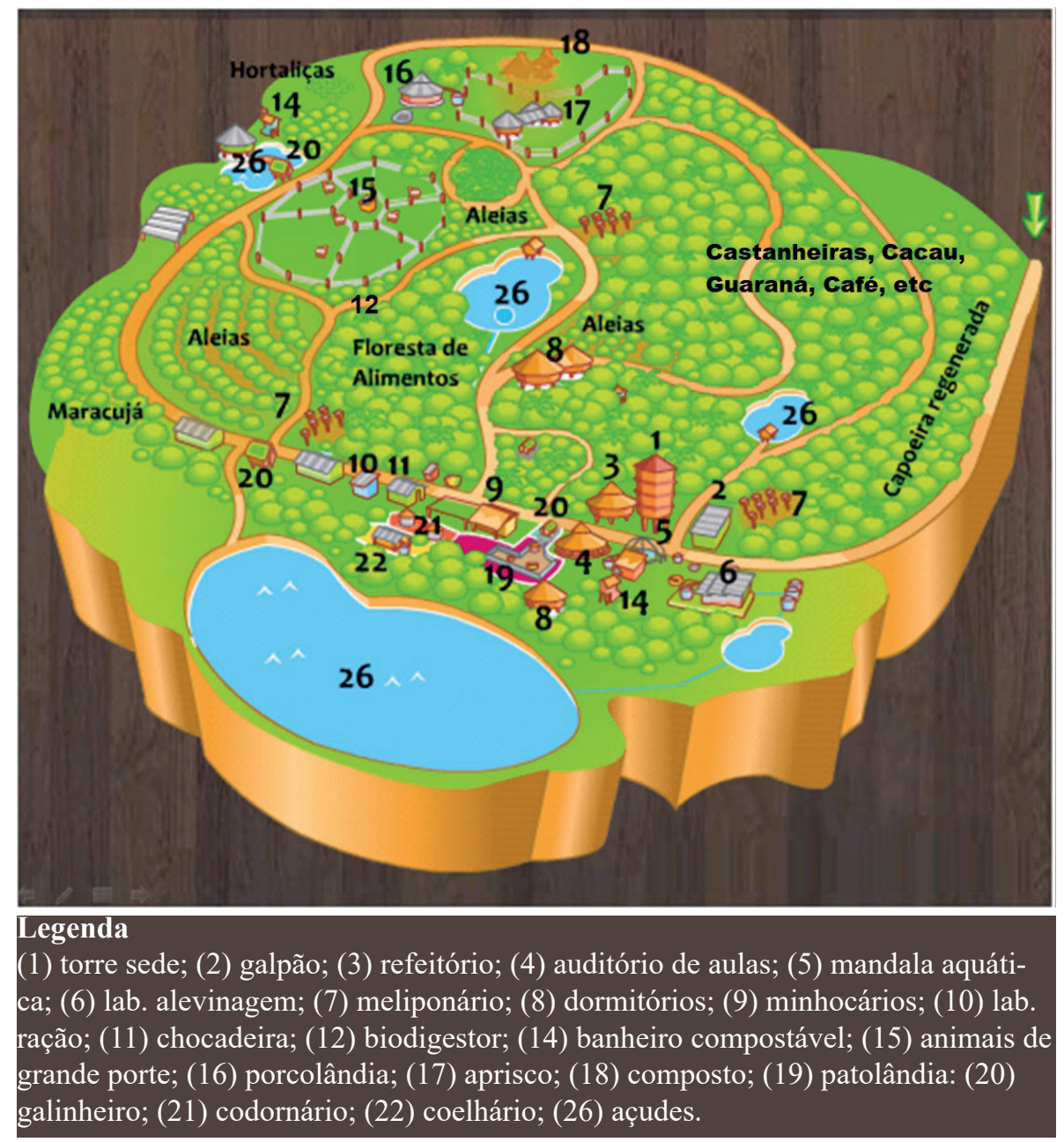

Fonte: Brito Junior (2015)

A UDP foi criada para ser um modelo de projeto de permacultura com um sistema autossuficiente em água e energia, com capacidade para atender todas as demandas da unidade. Foi um importante espaço para a realização de 18 cursos relacionados ao repasse de informações e técnicas de permacultura, design e consultoria, cultivo de peixes ornamentais, produção de ração orgânica, produção de hortaliças orgânicas/hortas em sistema de mandala e círculos de bananeira e muitos outros. Esses cursos atendiam a comunidade de pequenos produtores familiares e pessoas interessadas em desenvolver atividades produtivas dentro de um modelo de uso racional e sustentável dos recursos naturais.

Na UDP estão modelos de construção que podem ser replicados em comunidades rurais, como, por exemplo: o auditório subterrâneo, que pode servir como estrutura para as reuniões das comunidades, cursos de capacitação para os agricultores, como reforço escolar entre outras atividades, capaz de atender as necessidades das comunidades, e que pode ser construído aproveitando o sistema natural, como a ventilação, luz natural e cobertura com materiais recicláveis e naturais, como palha ${ }^{6}$.

6 A estrutura do auditório subterrâneo é feita abaixo do nível do solo, próximo à floresta, o que permite temperaturas mais amenas durante o dia, é construído também um tubo que permite a passagem de ar para dentro do espaço, funcionando como um ar-condicionado natural. Nesse sentido, para a cobertura do espaço, pode se usar palha ou outro tipo de material sustentável. 
Figura 3. Tanque com peixes, para a entrada de luz no auditório, e telhado feito de garrafas pet.
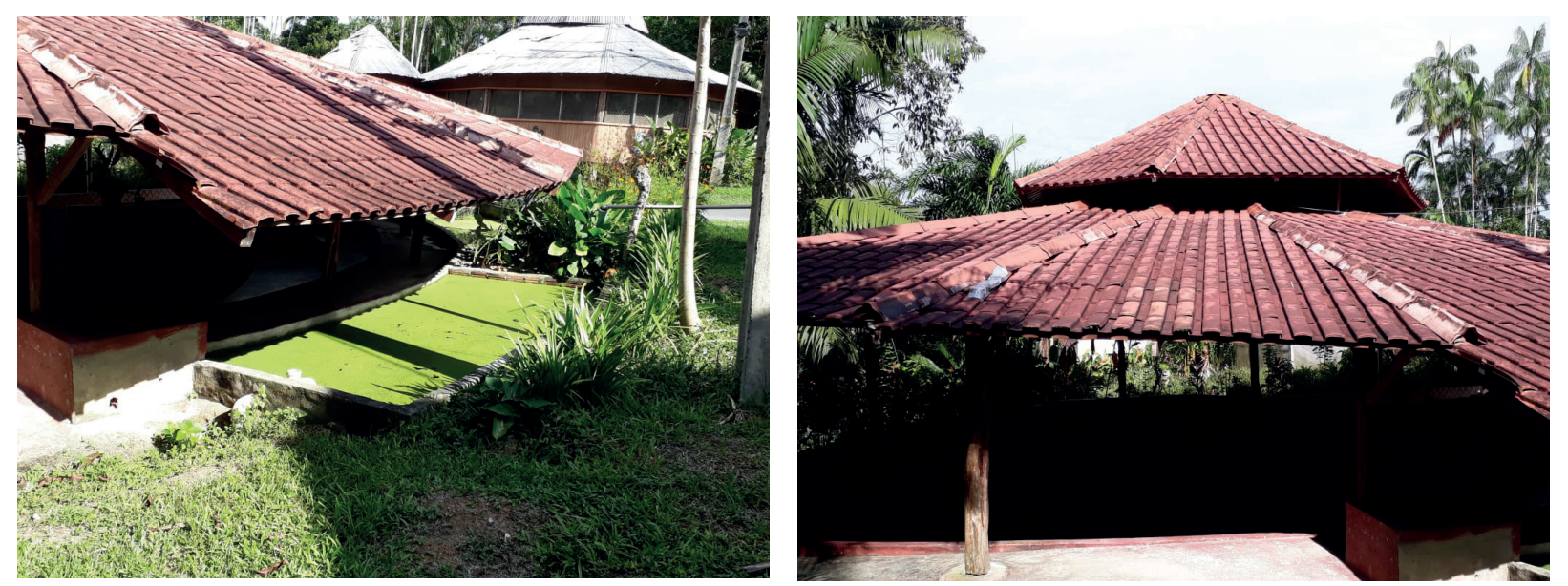

Foto: Alessandro Santos (2020).

Figura 4. Ar-condicionado natural e auditório subterrâneo visto de dentro.
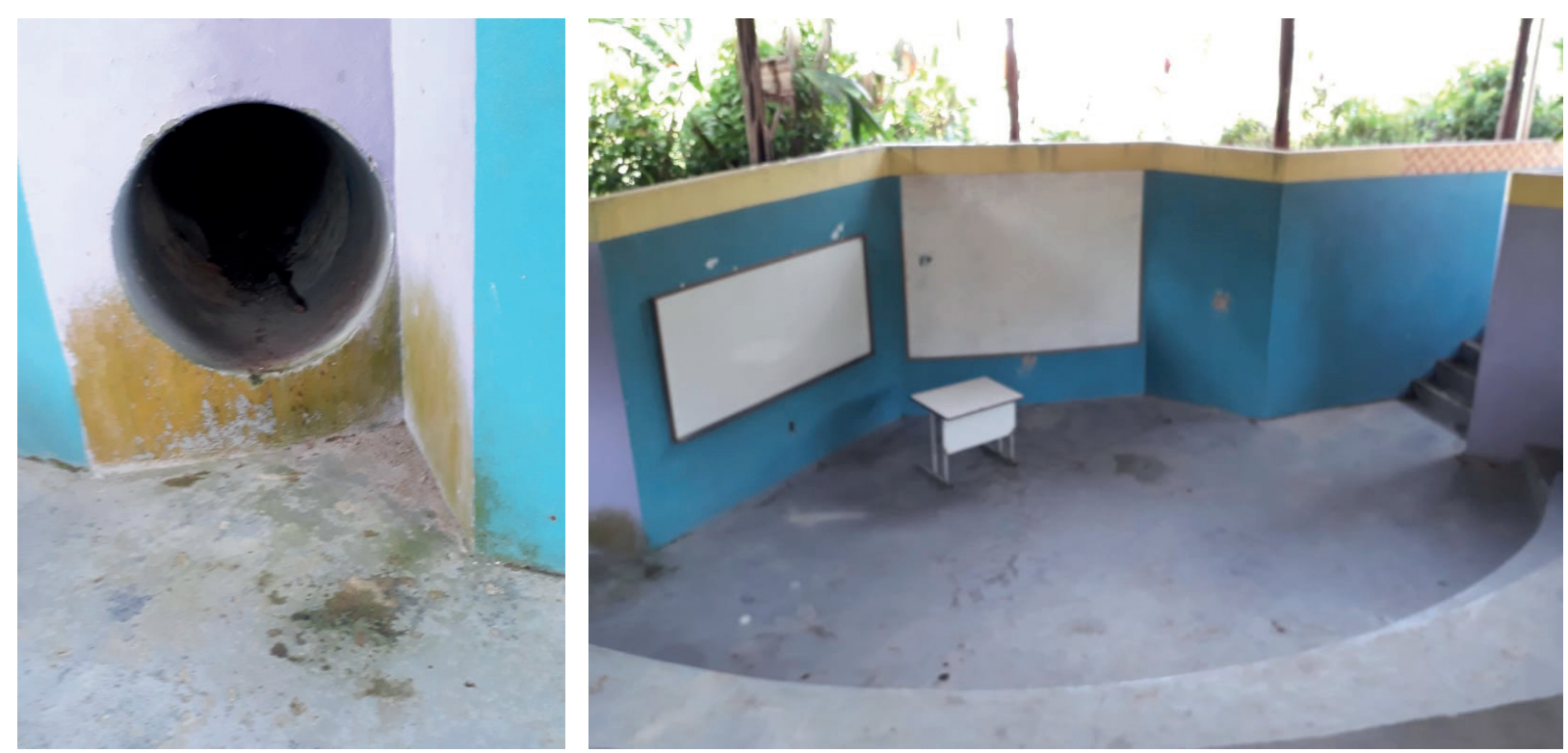

Foto: Alessandro Santos (2020).

Outra característica da permacultura presente e que podia ser vista na UDP era o design. Esse design, que ornamentava os espaços e corredores, era feito com o reaproveitamento de materiais como pneus, que são reutilizados como lixeiras e como vasos de plantas, embelezando assim o espaço e reaproveitando materiais, como pode ser visto na Figura 5.

Optou-se por telhas de plástico feitas com garrafas pet. Outro fator visto nesse auditório subterrâneo é a entrada de luz no local, feita por meio de tanques pequenos com peixes ornamentais, próximos ao espaço, que permite maior claridade, reduzindo, com isso, o custo com a energia. 
Figura 5. Design com pneus.
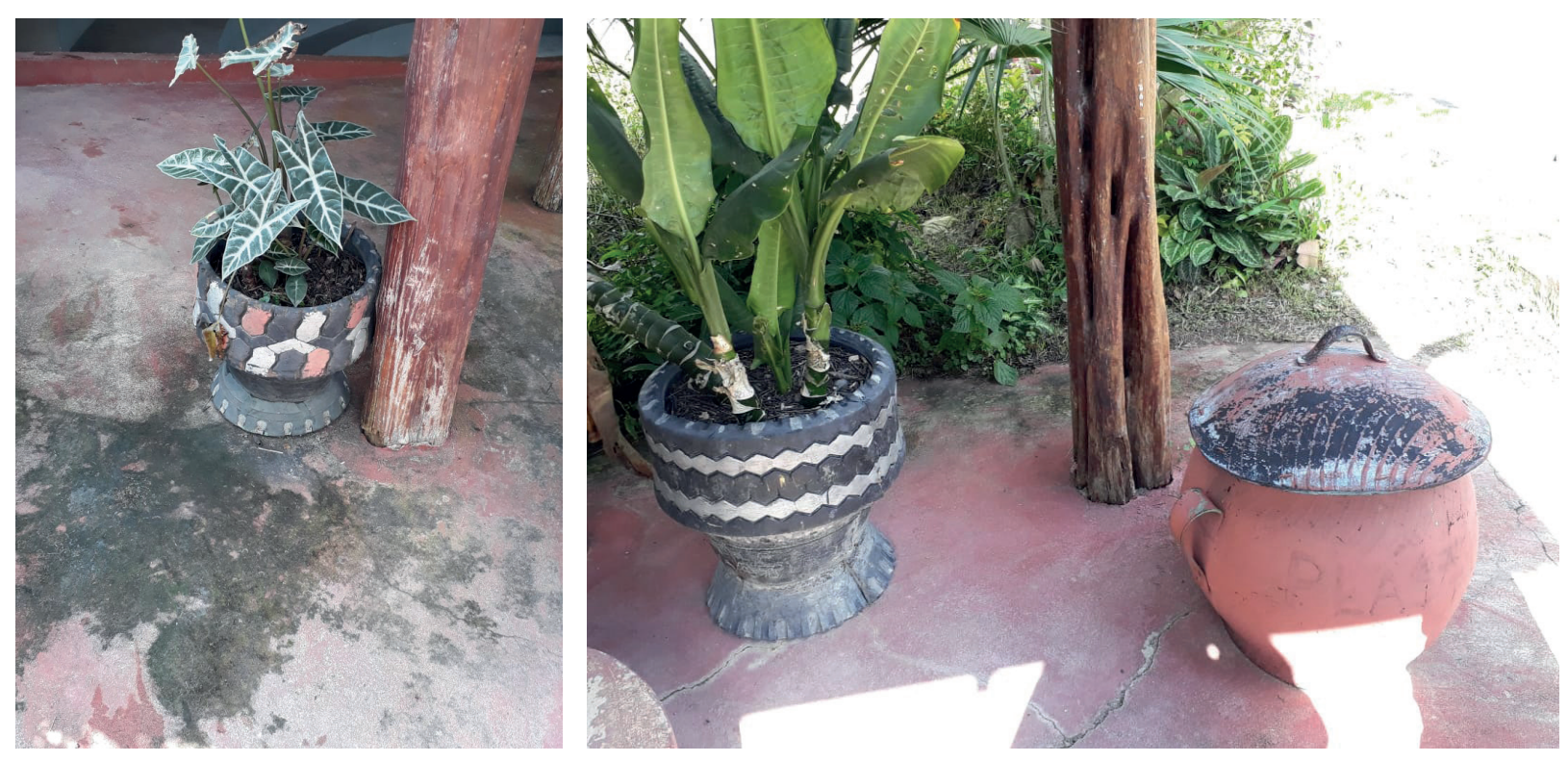

Foto: Alessandro Santos (2020).

Na UDP, como um sistema integrado, foi criada a porcolândia, que, além da criação de porcos, usava os dejetos para produzir gás de cozinha para o restaurante localizado dentro da unidade. Os dejetos eram transformados em gás por biodigestor. Para os seus criadores, esse modelo pode ser utilizado principalmente em fazenda ou comunidades que têm a criação de porcos como principal fonte de renda, contribuindo para a redução de $\mathrm{CO}_{2}$ na atmosfera, diminuindo o custo com a compra de gás de cozinha e diminuição de impactos ambientais ocasionados pelos dejetos dos animais.

Figura 6. Restaurante e porcolândia.
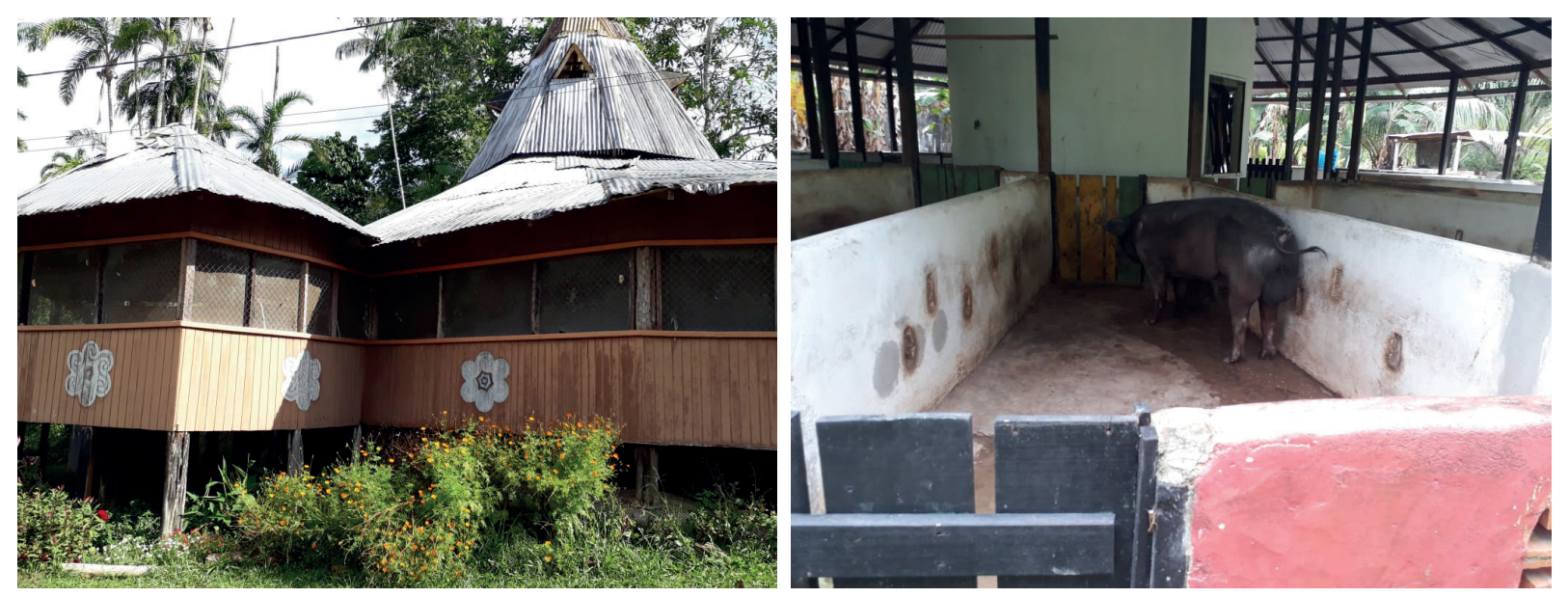

Foto: Alessandro Santos (2020).

O funcionamento da UDP ocorreu dentro de um arranjo institucional que envolveu a Escola Agrotécnica Federal em Manaus (EAFM), atualmente Ifam, e as fundações Avina ${ }^{7}$ e Daniel

Criada em 1994 pelo empresário suíço Stephan Schmidheiny. 
Dazcal $^{8}$. Essas duas fundações têm como foco apoiar projetos de sustentabilidade. A fundação Daniel Dazcal tem como principal foco de ação a divulgação de técnicas de permacultura para as populações carentes, orientando para que possam produzir seu próprio sustento, por vias ecologicamente corretas e por formas economicamente viáveis. Nesse arranjo estava também o IPA ${ }^{9} \mathrm{e}$ Permacultura América Latina (PAL).

\section{Observações a partir da visita à Unidade Demonstrativa de Permacultura (UDP)}

Uma das atividades da pesquisa foi a visita à UDP, conduzida pelo IPA, e hoje pelo Ifam, denominado atualmente de Centro de Referência em Agroecologia (CRA) ${ }^{10}$. Nessa visita um dos fatos que mais chamou atenção foi o estado de abandono das estruturas e equipamentos, que estão se deteriorando.

Segundo o professor João Soares (informação verbal) ${ }^{11}$, o motivo dessa deterioração é a ausência de recursos para a manutenção da UDP, já que os principais financiadores deixaram de custear o projeto, e provavelmente o Ifam não tem condições financeiras de manter a unidade. Em entrevista com João Soares fica evidente que a única fonte de captação de recursos da unidade era de projetos externos financiados por fundações não governamentais e, ao longo do tempo, não houve iniciativas voltadas à busca da autossustentação da unidade. Segundo o Professor João Soares de Araújo, o "IPA era responsável pelo desenvolvimento do projeto de permacultura e geralmente os projetos de financiamento duravam 2 anos. Nesse sentido, havia a necessidade de periodicamente elaborar novas propostas para a captação de recursos, após esse período" (informação verbal $)^{11}$.

$\mathrm{Na}$ entrevista também aparece divergência entre os financiados e os financiadores, no que se refere ao local e ao método para o desenvolvimento do projeto. Como diz Soares (1998): "houve um período de divergências em relação a área onde estava localizada a UDP, pois as organizações queriam o projeto de permacultura em uma comunidade ou numa área dos próprios financiadores" ... "Assim também, chegou um tempo em que a fundação Daniel Dazcal, principal mantenedora, quis realizar as suas atividades em outro espaço, contudo, Ali, que era o responsável pelo IPA, não permitiu e, assim, as demais entidades continuaram desenvolvendo o projeto no mesmo local".

\footnotetext{
8 Criada para homenagear o fundador da Tec Toy Daniel Efraim Dazcal.

9 Encerrou suas atividades em 2012, e a estrutura que formava a UDP passou a ser administrada pelo Ifam, unidade Zona Leste, sendo denominada como centro de referência em agroecologia. Esse espaço tem servido de referência para diversas visitas técnicas de vários órgãos, tais como: Empresa Brasileira de Pesquisa Agropecuária (Embrapa), Instituto de Desenvolvimento Agropecuário e Florestal Sustentável do Estado do Amazonas (Idam), Universidade Federal do Amazonas (Ufam), Universidade Estadual do Amazonas (UEA) e também para faculdades particulares e pesquisadores de outras instituições do País e interior do estado.

${ }^{10} \mathrm{O}$ Centro de Referência em Agroecologia (CRA) tem desenvolvido diversos projetos dentro da unidade, como as atividades de extensão, com a difusão e propagação de conhecimento sobre o cultivo de hortaliças, educação ambiental e a importância da reciclagem voltados para o público escolar. Existe, ainda, a produção de compostagem orgânica, que serve de insumo para aulas de campo dentro do espaço, e também disponibilizada para o cultivo de hortaliças e outros. No CRA também tem sido desenvolvido o Programa Institucional de Bolsas de Iniciação Científica (Pibic) e o Programa de Apoio à Iniciação Científica (Paic), desenvolvido por docentes e discentes do Ifam, como também de universidades particulares. As pesquisas desenvolvidas são nas áreas de plantas, criação de cultivares, entre outros. Essa pesquisa tem gerado artigos e trabalho de conclusão de curso (TCC) e assim disponibilizado conhecimento para a sociedade.

${ }^{11}$ Notícia fornecida por João Soares de Araújo, docente do Instituto Federal de Educação, Ciência e Tecnologia do Amazonas (Ifam), em entrevista ao bolsista de Iniciação científica Alessandro Carvalho dos Santos, em 10 de fevereiro de 2020.
} 
Outro aspecto que chama a atenção é a dispersão da equipe que conduzia o projeto, como relata João Soares:

[...] posteriormente, Ali recebeu uma proposta para trabalhar na África em 2009 e partiu. Ali e Carlos Miller eram responsáveis pela captação de recursos do IPA. Miller se mudou para o Rio de Janeiro, dificultando o processo de captação de recursos para a UDP. A fundação Daniel Dazcal, continuou ainda financiando a gestão até 2012. Após isso, os colaboradores que trabalhavam no IPA optaram em desenvolver outras atividades em outras localidades, deixando assim o projeto de Permacultura" (Informação verbal, $2020)^{12}$.

O relato de Soares (2020) expõe também a ausência de formação e de capacitação de novos gestores, concentrando as ações que visavam à sustentabilidade da UDP em algumas pessoas, e isso fragilizou a continuidade do projeto e, principalmente, a renovação dos quadros necessários para manter a gestão dele.

A situação da estrutura da UDP e dos equipamentos, depois de 8 anos após o encerramento do financiamento da mantenedora principal, fundação Daniel Dazcal, em 2012, pode ser observada nas fotos tiradas durante a visita.

Figura 7. Antigo espaço destinado ao viveiro de mudas e à elaboração de ração orgânica.
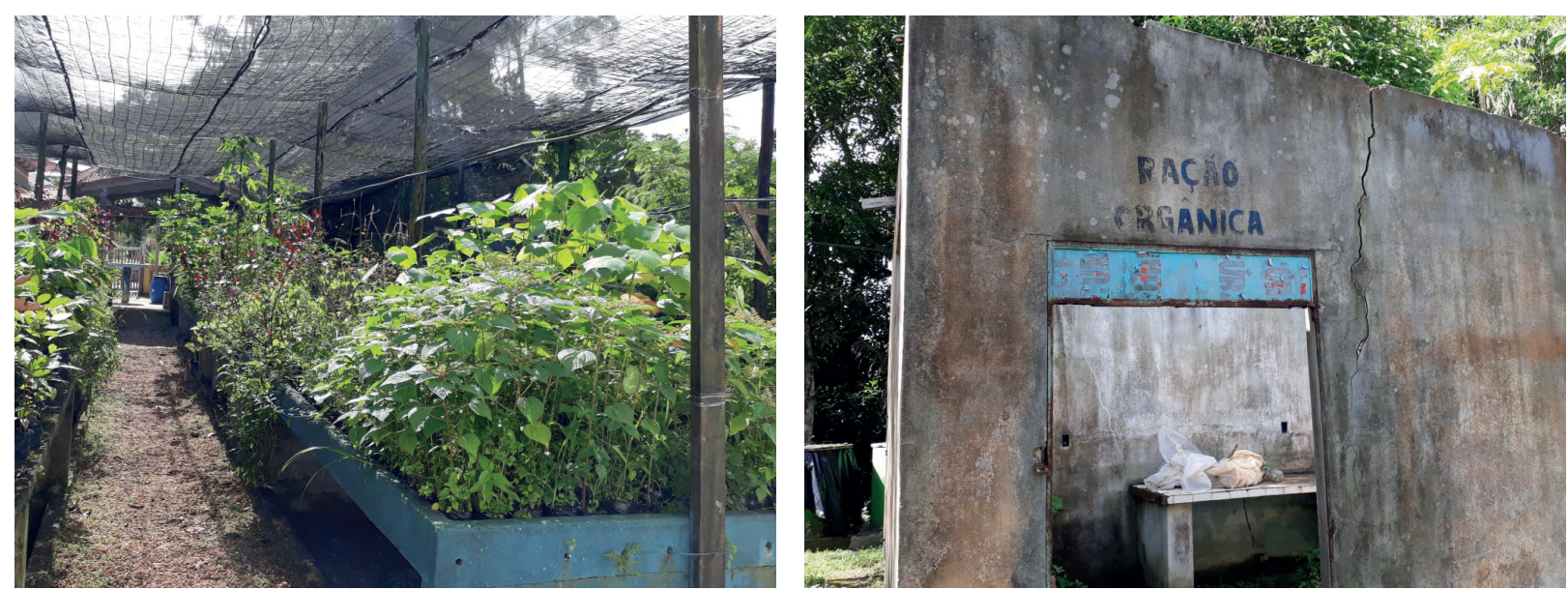

Fotos: Alessandro Santos, 2020.

\section{Considerações finais}

A permacultura segue princípios, técnicas e formas de potencializar a utilização dos recursos naturais e resíduos da indústria e de organizar o sistema de produção por meio do aproveitamento dos recursos disponíveis nas propriedades. Pode-se dizer que os projetos de permacultura ainda são incipientes no Brasil, entretanto mostram que essas inciativas já passaram por um

\footnotetext{
${ }^{12}$ Notícia fornecida por João Soares de Araújo, docente do Instituto Federal de Educação, Ciência e Tecnologia do Amazonas (Ifam), em entrevista ao bolsista de Iniciação científica Alessandro Carvalho dos Santos, em 10 de fevereiro de 2020.
} 
processo de amadurecimento e de experiência que podem se transformar em oportunidade de construção de um espaço harmônico, sustentável e de bem-estar para famílias rurais. Tais experiências demonstram que é possível a consolidação de um modelo sustentável, principalmente como alternativa para as comunidades de pequenos agricultores familiares.

Em nosso entendimento, a consolidação da ideia e proposta de expansão da permacultura, para que a comunidade adote esse sistema de organização e uso dos recursos naturais para o desenvolvimento dessa forma de agricultura, necessita de uma política de acompanhamento técnico, de cooperação interinstitucional, de recursos financeiros e de uma comunicação tecnológica adequada à realidade vivenciada pelos agricultores, público-alvo das propostas.

Estamos diante de uma crise generalizada e global não somente econômica, ecológica ou social, mas uma crise do próprio sentido da vida e de nossa sobrevivência como espécie, uma crise de nossa forma de pensar e agir no mundo. Sobreviveremos a ela à medida que formos capazes de construir uma nova racionalidade ambiental que possa responder aos desafios presentes, como afirma Medina (1999, p. 24).

A experiência do IPA demonstrou como a permacultura pode ser uma alternativa sustentável nos seus princípios e com suas técnicas. Também evidencia o aspecto de sustentabilidade quando se analisa o conjunto das atividades organizadas, em que as construções mostram aspectos da harmonia e sustentabilidade em consonância com a necessidade das pessoas. A sustentabilidade de uma forma de agricultura como a permacultura está na integração de todos os elementos que fazem parte do ambiente. A experiência do IPA, que criou a UDP, contava com vários cursos ligados a permacultura, modelos de construções replicáveis em comunidades rurais, como, por exemplo, o auditório subterrâneo, que pode servir como estrutura para as reuniões das comunidades, cursos de capacitações para os agricultores, reforço escolar, entre outras atividades que poderiam ser atendidas considerando a necessidade da comunidade.

\section{Agradecimentos}

Francisco Pereira de Brito Júnior

João Soares de Araújo

Instituto Federal do Amazonas (Ifam) - Unidade Zona Leste

Recebeu Apoio da Fundação de Amparo à Pesquisa do Estado do Amazonas (Fapeam).

\section{Referências}

AMBIENTE BRASIL. Permacultura. Ambiente Brasil. 2020. Disponível em: https://ambientes.ambientebrasil.com.br/florestal/agrossilvicultura/permacultura.html. Acesso em: 22 jan. 2020.

ANA. Sustentabilidade e reutilização de água. Viva Decora, p. 1, 30 jan. 2015. Disponível em: https:// www.vivadecora.com.br/revista/sustentabilidade-e-reutilizacao-de-agua. Acesso em: 15 jan. 2020. 
ARCOS, A. M. P. Caracterização dos agroecossistemas em um Assentamento de Reforma Agrária no Amazonas: possibilidades de mudança no modelo de produção. 2015. $86 \mathrm{f}$. Trabalho de Conclusão de Curso (Curso Superior de Tecnologia em Agroecologia) - Instituto Federal de Educação, Ciência e Tecnologia do Amazonas - Campus Manaus Zona Leste, Manaus. Disponível em: http://repositorio.ifam. edu.br/jspui/bitstream/4321/266/1/TCC\%20OFICIALADRIACOM\%20A\%20FICHA.pdf. Acesso em: 14 maio 2020.

ARKCOLL, D. B. Considerações sobre a produção de alimentos por árvores e florestas. Acta Amazônica, v. 12, n. 2, p. 247-249, 1982. Disponível em: https://www.scielo.br/scielo.php?pi$\mathrm{d}=$ S0044-59671982000200247\&script=sci_abstract\&tlng=pt. Acesso em: 15 abr. 2020.

ASSIS, R. L. de; ROMEIRO, A. R. Agroecologia e agricultura orgânica: controvérsias e tendências. Desenvolvimento e Meio Ambiente, n. 6, p. 67-80, jul./dez. 2002. Disponível em: https://revistas.ufpr. br/made/article/view/22129/14493. Acesso em: 22 mar. 2020.

BRASIL. Ministério do Meio Ambiente. Secretaria de Extrativismo e Desenvolvimento Rural Sustentável. Departamento de Desenvolvimento Rural Sustentável. Curso de Bioconstrução. Brasília, DF, 2008.

BRITO JUNIOR, F. P. de. Relatório das atividades desenvolvidas no Centro de Referência em Agroecologia/Permacultura no período de 2012 a 2015. Manaus: IFAM/CMZL, 2015. Disponível em: https://www.docsity.com/pt/relatorio-cra-2012-a-2015/4877820. Acesso em: 15 fev. 2020.

CARVAlHO, A. S. de; REZENDE, M. G. G.; FRAXE, T. de J. P. Adaptabilidade humana e estratégias de conservação ambiental na comunidade São José (Careiro da Várzea, AM). Revista Terceira Margem Amazônia, v. 5, n. 13, p. 20-31, jul./dez. 2019. Disponível em: http://www.revistaterceiramargem.com/ index.php/terceiramargem/article/view/304. Acesso em: 22 mar. 2020.

CONFEDERAÇÃO DAS COOPERATIVAS DE REFORMA AGRARIA DO BRASIL - CONCRAB. Sistema Cooperativista dos Assentados. São Paulo, 1997. (Caderno de Cooperação Agrícola, n. 5).

COSTA, M. S. B. da. et al. O consumo de orgânicos: reflexões para sua popularização como fomento à agricultura sustentável. Revista Terceira Margem Amazônia, v. 5, n. 13, p. 119-128, 2019. Disponível em: http://www.revistaterceiramargem.com/index.php/terceiramargem/article/view/311. Acesso em: 22 mar. 2020.

DESLAURIERS, J. P. Recherche qualitative - guide pratique. Montreal: McGraw-Hill, 1991.

FACHIN, O. Fundamentos de metodologia. 3. ed. São Paulo: Saraiva, 2010.

FUNDAÇÃO DANIEL DAZCAL. Relatório de atividades 2008. Manaus, 2008. 18 p. Disponível em: http://www.fdd.org.br/html/reldeatividadesfdd030709.pdf. Acesso em: 22 fev. 2020.

GERHARDT, T. E.; SILVEIRA, D. T. Métodos de pesquisa. Porto Alegre: Editora da UFRGS, 2009.

GIL, A. C. Como elaborar um projeto de pesquisa. 4. ed. São Paulo: Atlas S/A, 2002.

HENDERSON, D. F. Permacultura: as técnicas, o espaço, a natureza e o homem. 2012. 87 f. Monografia (Bacharelado em Ciências Sociais) - Universidade de Brasília, Instituto de Ciências Sociais, Brasília, DF.

KRZYZANOWSKI, R. F. Novas tecnologias em assentamentos humanos: a permacultura como proposta para o planejamento de unidades unifamiliares em Florianópolis. 2005. $144 \mathrm{f}$. Dissertação (Programa de Pós-Graduação em Engenharia de Produção) - Universidade Federal de Santa Catarina, Centro Tecnológico, Florianópolis. Disponível em: https://repositorio.ufsc.br/handle/123456789/101714. Acesso em: 11 abr. 2020. 
LEGAN, L. O que é esta coisa - MULCH? Saracura Blog, 8 fev. 2016. Disponível em: https://saracura. org/2016/02/08/o-que-e-esta-coisa-mulch/. Acesso em: 22 abr. 2020.

MARCONI, M. de A.; LAKATOS, E. M. Técnicas de pesquisa. 6. ed. São Paulo: Atlas, 1999.

MEDINA, N. M. Educação ambiental: uma metodologia participativa de formação. Petrópolis: Vozes, 1999.

MOURA NETO, E. L.; NOGUEIRA, I. C. C. Efeito da cobertura morta sobre a produção de quatro cultivares de coentro no município de Mossoró - RN. Horticultura Brasileira, v. 12, n. 1, p. 93, 1994.

NODARI, R. O.; GUERRA, M. P. La bioseguridad de las plantas transgénicas. In: BARBACENA, A. et al. (Org.). Los transgénicos en América latina y el Caribe: un debate abierto. Santiago: Editora Nações Unidas, 2015.

SANTORO, R.; PENTEADO, C. Bioconstrução: utilizando o conhecimento ecológico para a criação de construções saudáveis. Trabalho apresentado no 13. Encontro da Associação Nacional de Pós-Graduação e Pesquisa em Planejamento Urbano e Regional, Florianópolis, 2009.

SECA, A. I. et al. Empreendimentos ecoturísticos como fator de desenvolvimento sustentável na comunidade ribeirinha São João do Tupé, Manaus, Amazonas. Revista Terceira Margem Amazônia, v. 5, n. 13, p. 48-60, 2019. Disponível em: http://revistaterceiramargem.com/index.php/terceiramargem/article/ view/306. Acesso em: 25 abr. 2020.

SOARES, A. L. J. Conceitos básicos sobre permacultura. Brasília, DF: MA/SDR/PNFC, 1998. 53 p. Disponível em: https://permacoletivo.files.wordpress.com/2008/05/conceitos_basicos_permacultura.pdf. Acesso em: 23 abr. 2020.

VIEIRA, I. Círculo de bananeiras. Setelombas, 14 out. 2006. Disponível em: https://www.setelombas. com.br/2006/10/circulo-de-bananeiras/. Acesso em: 22 mar. 2020.. 
